\title{
Letrônica
}

\section{Afinal, a quem pertence uma carta?}

By the way, whom a letter belongs to?

Leandro Garcia Rodrigues ${ }^{1}$

Doutor e Pós-Doutor em Estudos Literários pela PUC-Rio Organizador ditas seguintes Correspondências recíprocas: Correspondência Carlos Drummond de Andrade e Alceu Amoroso Lima (UFMG, 2014), Cartas de Ternura em Tempos de Ditadura - Frei Betto e Leonardo Boff Escrevem a Alceu Amoroso Lima (Vozes, 2014) e Correspondencia Mario de Andrade e Alceu Amoroso Lima (EDUSP, 2015 - em fase de produçáo com o IEB). Atualmente, e professor adjunto de Literatura Brasileira proviveridade Catolica de Petropolk
RESUMO: Cada vez mais, os estudos sobre o Gênero Epistolar, no Brasil, avançam e já deixam a sua marca. Desde 2000, com a publicação do primeiro volume da Coleção Correspondência Mário de Andrade, organizada pelo Instituto de Estudos Brasileiros da USP, a Epistolografia tem recebido uma considerável sistematização nos Estudos Brasileiros. Por esta razão, certas questões e dúvidas vêm surgindo ao longo destas pesquisas. A partir de uma pergunta - a quem pertence uma carta - desenvolvi as principais ideias deste artigo, já que esta dúvida tem permeado consideravelmente o trabalho dos organizadores de Correspondência. A partir de propostas extraídas de algumas cartas e outros textos teóricos, tento entender e debater o destino de uma carta, seu pertencimento - individual ou coletivo? - e problemas legais e morais envolvidos nesta problemática.

PALAVRAS-CHAVE: epistolografia; carta; literatura.

ABSTRACT: More and more, the researches done concerning the Epistolary Gender, in Brazil, have gone ahead. Since 2000, when the first volume of the Mario de Andrade's Correspondence Collection was published, organized by the Brazilian Studies Institute (USP), Epistolography has had a considerable systematization within the Literary Studies. Because of that, certain questions and doubts have come out to be solved. Starting with a question - Whom a letter belongs to? - I have written the main ideas of this paper, once this specific doubt has spread itself throughout the Correspondences' organizers work. Questioning some particularly theories and texts, we can debate a letter's destiny, its belonging - individual or not - as well as some legal and moral problems within such task.

KEYwORDS: epistolography; letter; literature. 
Como foi que neste mundo alguém chegou à ideia de que pessoas podem se comunicar umas com as outras através de cartas? Podemos pensar sobre uma pessoa distante, e podemos agarrar uma pessoa que está próxima - tudo o mais vai além da força humana. Escrever cartas, entretanto, significa desnudar-se diante de fantasmas, algo pelo qual eles aguardam avidamente.

(FRANZ KAFKA)

$\mathrm{Q}$ uando Philippe Lejeune escreveu seu pequeno ensaio-crônica $A$ Quem Pertence Uma Carta?, inserido em Pour l'autobiographie (Paris: Seuil, 1998), estava o crítico francês tocando num dos principais problemas concernentes às fronteiras do Gênero Epistolar - o direito de posse numa correspondência, especialmente daquelas cartas que se tornaram públicas via publicação com ou sem o consentimento de uma das partes. Entretanto, este não é o único problema que enfrentam os pesquisadores de documentos epistolares, especialmente por estarmos lidando com uma escrita complexa que flutua entre as fronteiras do público e do privado, do autobiográfico e da encenação, da verdade e da ficção, do histórico e do literário. Nossa intenção neste ensaio é problematizar algumas dessas questões, não objetivando uma "solução final" para aquelas que serão apresentadas. Ao contrário, queremos levantar hipóteses e discuti-las, exemplificando e demonstrando a dificuldade de abordagens essencialmente ortodoxas para se compreender esta problemática.

A pergunta de Lejeune possui uma atualidade desconcertante, especialmente numa época na qual pululam publicações de cartas e outros escritos íntimos de escritores e demais personalidades da vida pública. 0 "surto" de (auto)biografias nas livrarias é algo assustador, o que nos leva a acreditar numa espécie de espetacularização da própria vida, o que nos permite fazer outra pergunta semelhante à de Lejeune: a quem pertence a narrativa da vida?, especialmente daqueles cujas vidas são uma espécie de performance que excede do privado ao público. Mas voltando à questão epistolar, cito o próprio Lejeune:

Uma vez na caixa [dos Correios], a carta passa a pertencer ao destinatário. Uma vez postada, reavê-la significa roubar. [...] A partir do momento em que é postada, torna-se fisicamente propriedade do destinatário e quando este morre, de seus herdeiros. [...] Mesmo postada, a carta continua sendo, intelectual e moralmente, propriedade do seu autor - e, depois da sua morte, de seus herdeiros; mas o exercício desse direito poderá ser limitado, de fato, se o autor não estiver mais com a carta (salvo no caso de uma cópia ter sido conservada). (LEJEUNE, 2008, p. 253)

O crítico apresenta uma série de argumentos de caráter um tanto mais legal, jurisprudente, baseado na lei francesa de 1957 que versou sobre os direitos da propriedade intelectual. Na prática cotidiana das publicações, percebemos um certo desvio de algumas normas legais. É comum encontrarmos destinatários alegando o direito de posse de todo o material epistolar recebido, ao longo da correspondência, daquela pessoa (o remetente) que escreveu não tanto para si, mas para o outro.

Neste sentido, é sintomática uma máxima de Michel Sérres: "Eu sou vários outros" (SÉRRES, 2009, p. 9), isto é, a experiência pessoal passa, inevitavelmente, pelo filtro existencial do outro, do interlocutor - e nas cartas - do destinatário, num complexo jogo de dialogismo epistolar. Daí o fato de que muitos destes relegam para si o direito de leitura, de posse e até mesmo de divulgação das cartas recebidas.

Numa via um tanto complementar, temos o exemplo de Mário de Andrade, certamente o artista brasileiro que melhor explorou as fronteiras - tensas e complicadas - da escrita epistolar. Mário teve inúmeros destinatários, célebres ou anônimos, que enviavam à Rua Lopes Chaves 546, no bairro da Barra Funda, em São Paulo, um "mundo de cartas”. Mário sofreu com certos 
pesadelos éticos quanto ao destino que deveria ser dado ao seu acervo de cartas e outros escritos íntimos, tanto que em 1944, um ano antes do seu falecimento, escreveu uma espécie de carta-testamento ao seu irmão mais velho, advertindo-o acerca do destino a ser dado à sua correspondência (especialmente a passiva), esta deveria "ser fechada e lacrada pela família e entregue para só poder ser aberta e examinada cinquenta anos depois de [sua] morte" (ANDRADE e ALVARENGA, 1974, p. 32).

Num outro momento do seu epistolário, mais tenso e preocupado, encontramos Mário escrevendo a Murilo Miranda num tom de revolta e quase ameaçador em relação à publicação das suas cartas:

Meu Deus! o que mais me horroriza são as minhas cartas, egoísmo agindo. Devia ser proibido a mostra pública de cartas particulares, por lei governamental. Como si um escritor, um artista, pelo fato de ter uma vida pública, não pudesse ter uma vida particular! Francamente, é infame. Rasguei todas as cópias que fiz, perdi o dia, e isso de cartas a mim mandadas, nenhuma será publicada enquanto eu viver. Você não pensa que não imaginei destruir agora todas elas. Imaginei sim, mas não posso, não tenho força moral pra tanto. Sei que estou numa contradição interna medonha. Assim com uma vontade de deixar isso, como vou mesmo deixar, pra uma instituição pública mas com a ressalva de só poder ser aproveitado num sentido que não seja pejorativo [...] e declaro solenemente, em estado de razão perfeita, que quem algum dia publicar as cartas que possuo ou cartas escritas por mim, seja em que intenção for, é filho da puta, infame, canalha e covarde. Não tem noção da própria e alheia dignidade. (ANDRADE, 1981, p. 158-159)

Na tensão de decidir qual o destino dar às suas cartas, Mário faz alusão a uma das estratégias mais comuns: a destruição completa dos escritos íntimos, principalmente quando estes são compostos por cartas e diários pessoais. Retorno às teorias de Philippe Lejeune, mas agora utilizo suas ideias expressas no ensaio How do Diaries End? (Como os Diários Terminam?), escrito em 2001. Embora analise tal ponto de vista na perspectiva de diários íntimos, afirmo que é possível certa adaptação temática e metodológica em relação à Correspondência. Segundo Lejeune, há algumas estratégias para se terminar um diário:

a) um final voluntário e decidido (para um diário que ainda não foi destruído);

b) a destruição [definitiva] do diário (um final enérgico e definitivo);

c) uma releitura [avaliação];

d) publicação (uma transformação que assume algum tipo de acabamento). ${ }^{1}$

Em geral, quando se destrói tais textos, o autor é determinado e a ação é definitiva, como afirma Mário a Murilo Miranda: "Rasguei todas as cópias que fiz", "Você não pensa que não imaginei destruir agora todas elas." (ANDRADE, 1981, p. 158). Em muitos casos, a destruição é feita através do fogo, numa atitude mista de eliminação e expurgação, uma espécie de liturgia purificadora e, por isso mesmo, catártica.

Outra questão interessante é a ressalva intransigente de Mário: “declaro solenemente, em estado de razão perfeita, que quem algum dia publicar as cartas que possuo ou cartas escritas por mim, seja em que intenção for, é filho da puta, infame, canalha e covarde" (Idem, p. 159). Ora, sabemos que foi justamente Manuel Bandeira, um dos seus grandes amigos e correspondentes mais assíduos, quem primeiro publicou as cartas recebidas de Mário ao longo de mais de vinte anos de amizade. Bandeira, na década de 50, organizou e deu à luz o importante epistolário que manteve com o autor de Macunaíma, todavia, fez diversas censuras e cortes nos textos originais, certamente por temer a reação de muitos que foram citados ao longo da Correspondência e que ainda estavam vivos e atuantes. Para Bandeira, a razão de publicar tais cartas se dava, exclusivamente, por ver nelas uma importância singular do ponto de vista crítico-literário, biográfico e cultural.

Disponível do site: <http://www.highbeam.com/doc/1G1-75832665.html>. Acesso em: 09 mar. 2011 tradução minha e pessoal. 
Tal aspecto crítico tem sido constantemente defendido por muitos que se ocupam a organizar e analisar epistolários, isto é, certas cartas iluminam algumas dúvidas a respeito de obras e autores, bem como servem como uma espécie de "espelho" sintomático a refletir determinadas nuances do próprio processo de gestação e criação da obra. A este respeito, Vincent Kaufmann esclarece que

A correspondência é para alguns escritores, independentemente de seu eventual valor estético, uma passagem obrigatória, um meio privilegiado de ter acesso a uma obra, o elo que falta entre o homem e a obra. As correspondências representam um corpus ao mesmo tempo superabundante e sempre lacunar. (KAUFMANN, 1990, p. 80)

Nas trocas epistolares com um cunho mais teórico e ensaístico, a carta pode também funcionar como uma espécie de campo experimental para a construção estilística dos respectivos autores, bem como para expor a diversificação das experiências de ambos: comentários acerca da vida social, cultural e política de um determinado momento, as mudanças das conjunturas intelectual e ideológica que permeiam a vida de cada remetente, os meandros do processo de criação, as dúvidas do que escrever - e como escrever -, os assuntos a serem explorados ou relegados quando do momento da escrita. A carta se torna, desta forma, uma oportunidade - um lócus - para construção de pensamentos e ideias.

Desta forma, podemos dizer que determinadas Correspondências, especialmente aquelas mais "pensadas" e organizadas, funcionam como verdadeiros laboratórios de criação. Pensemos nas cartas de Alceu Amoroso Lima a Nestor Víctor, nas quais os dois críticos discutem, concordam e divergem acerca da práxis e da função da Crítica Literária no Brasil. Ou então as cartas dos artistas modernistas da fase heroica paulista, verdadeiros documentos que testemunham não apenas as inquietações dos primeiros "incêndios futuristas", mas principalmente um intrincado jogo de estilística e experimentalismos próprios do início de qualquer movimento artístico de vanguarda. E ainda um último exemplo: as cartas dos jovens poetas de Cataguases criadores da Revista Verde, que tinham em Mário e Oswald de Andrade os seus referenciais seguros de qual caminho literário a ser seguido, qual trilha ideológica e estética era a mais adequada naquele ideal de atualização da cultura nacional, isto é, cartas entre mestres e discípulos. A respeito desta dimensão da Correspondência, explica Marcos Antônio Moraes:

O comungar da carta se espelha no desejo de estar junto, na constante troca de opinião, nas sugestões contestadas ou aceitas. O 'outro', no diálogo epistolar, concorre muitas vezes para a realização artística, funcionando como termômetro da criação. A carta é 'laboratório' onde se acompanha o engendramento do texto literário em filigranas, desvendando-se elementos de constituição técnica da poesia e seus problemas específicos. Propicia a análise (gênese e busca de sentido) e torna manifesto as motivações externas que 'precisam a circunstância' da criação. A escrita epistolográfica proporciona a experimentação linguística e o desvendamento confessional. (MORAES, 2001, p. 14)

Todos esses argumentos nos levam a repetir e analisar a pergunta que deu início às nossas reflexões: afinal, a quem pertence uma carta?

Trata-se de uma questão complexa e até mesmo perigosa, já que determinadas missivas adquiriram valor e função públicos, especialmente se levarmos em consideração o conteúdo das mesmas que servem para compreendermos momentos e particularidades da nossa própria história cultural. Neste sentido, a correspondência trocada entre o crítico e pensador católico Alceu Amoroso Lima com Frei Betto, escritor e ideólogo da Teologia da Libertação. Fiz a organização deste epistolário, que será publicado brevemente pela Editora Vozes, o que me possibilita uma maior "aproximação" com este conjunto epistolar, que totaliza vinte e duas missivas. 
Os assuntos são variados, todavia, os mais recorrentes dizem respeito ao terrorismo implantado no Brasil a partir do Golpe de 64, bem como a tensa relação entre a Igreja e o Estado a partir deste episódio, especialmente por conta das inúmeras prisões, torturas e mortes que vitimaram religiosos e leigos por todo o país. O próprio Frei Betto foi uma destas vítimas, uma vez que permaneceu quatro anos encarcerado, momento este extensamente narrado nas suas cartas endereçadas a Alceu Amoroso Lima.

Nas diversas cartas escritas e publicadas por Frei Betto, não apenas aquelas endereçadas a Alceu, percebemos um sentimento acima do indivíduo, são "cartas para todos", existe um duplo destinatário: a) a pessoa física a quem a missiva é endereçada e b) o destinatário geral, desconhecido, plural. São "cartas para os outros", suas cartas - cartas de todos. Lembrando Contardo Calligaris (1997), analisando os mais diferentes tipos de textos autobiográficos:

O escrito autobiográfico implica uma cultura na qual, por exemplo, o indivíduo (seja qual for sua relevância cultural) situe sua vida ou seu destino acima da comunidade a que ele pertence, na qual ele conceba sua vida não como uma confirmação das regras e dos legados da tradição, mas como uma aventura para ser inventada. Ou ainda uma cultura na qual importe ao indivíduo durar, sobreviver pessoalmente na memória dos outros. (CALLIGARIS, 1997, p. 2)

Este "sobreviver pessoalmente na memória dos outros" estava diretamente implicado na ideia de denúncia, isto é, a carta funcionando como alternativa de explodir as barreiras físicas da prisão, é o destinatário múltiplo, é a carta endereçada a toda e qualquer pessoa de bem que pudesse - a partir da sua leitura - estabelecer qualquer elo de solidariedade com o remetente encarcerado. Tal fato levou Alceu Amoroso Lima a escrever o intrigante artigo "Documento para Amanhã", publicado no Jornal do Brasil, em 4 de maio de 1973, no qual ele afirmou:
A mocidade do meu tempo vibrava, com os que se haviam insurgido, como Tiradentes, contra o Estado colonial. A mocidade de hoje também vibra, mas sobretudo sofre na carne, com os que se insurgem contra o Estado policial. Haja à vista a onda recente de assassinatos e prisões, enquanto os jovens dominicanos ordenados ou não, continuam a cumprir sua pena de prisão sem nenhuma ignomínia, por terem praticado a virtude da hospitalidade aos perseguido. [... Entre eles se destaca a figura ímpar de Frei Beto, Carlos Alberto Libanio Christo, cujas cartas da prisão representam um dos mais altos documentos da mais pura espiritualidade, comprometido com a realidade concreta e não apenas especulativa, se não o mais alto de toda a nossa literatura. [...] É a voz dos grandes profetas que fala por esse jovem de 20 e poucos anos, em uma cela dos 'subterrâneos da História'. [...] Não sei que documentos ficarão de nossos tempos para o futuro. Sei, apenas, que um deles será este. (apud RODRIGUES, 2015, p. 141)

Alceu teve a clara sensação de que ele não era o único destinatário das cartas de Frei Betto, tanto que publicou diversos trechos das mesmas nas suas inúmeras crônicas jornalísticas, usando o espaço do jornal como tribuna de denúncia e extravasamento destas mesmas missivas, tornando-as "documento para amanhã"; todavia, um amanhã presentificado, um amanhã que urgia - no agora da leitura - uma tomada de decisão por parte dos leitores, um posicionamento crítico acerca dos subterrâneos da nossa História contemporânea. Ou seja, a epistolografia contendo uma possibilidade natural e intrínseca de provocar mutações ideológicas nos seus possíveis destinatários - evoco o plural - influenciando novas ideias e atitudes, permitindo a reflexão, levando-nos a conceber a carta como uma "categoria transhistórica" do discurso, com múltiplos cruzamentos e distintas direções de manifestação e representação.

As cartas trocadas entre Frei Betto e Alceu Amoroso Lima, especialmente aquelas da época da prisão do frade dominicano, são uma espécie de brado de e por justiça, um grito que reverberou para além do respectivo destinatário destas mesmas cartas, causando uma espécie de movimento catártico nestes mesmos destinatários, gerando uma recepção produtiva do ponto de vista reflexivo pela projeção de uma determinada subjetividade. Na longa 
carta enviada a Alceu, em 22 de fevereiro de 1970, Frei Betto deixa claro a necessidade de se buscar a justiça e punir aqueles que a violam:

Embora processados por atividades, sofremos punição religiosa. Fomos proibidos de celebrar missa, e três estudantes dominicanos foram impedidos pela Auditoria de renovarem seus votos religiosos, conforme a Igreja exige. Resta-nos saber quem tem o direito de nos suspender de ordens: a autoridade militar ou a autoridade eclesiástica? 0 juiz alegou que a profissão religiosa seria 'uma promoção aos dominicanos'. Desde quando renovar a opção pela vida religiosa é uma 'promoção' ofensiva ao Estado brasileiro? Estamos sendo religiosamente punidos por quê? Nada está provado contra nós, nem mesmo temos culpa formada. Tais medidas só se justificam num regime que persegue a Igreja. Os dominicanos que deveriam renovar os votos no dia 11 de fev. são os frades Tito de Alencar Lima, Roberto Romano e Yves do Amaral Lesbaupin. [...] Reze pelos que neste país lutam pela justiça, pelos presos políticos e suas famílias, pelos que morreram nas torturas, pelo frei Tito. Estaremos unidos ao sr. na mesma oração. Ela é a garantia dessa liberdade interior que ninguém pode arrancar de nós. (RODRIGUES, 2015, p. 70)

É uma outra perspectiva de encararmos o texto epistolar: não apenas como o "outro lado" da obra do seu autor, o seu reverso, mas como documento que não lhe pertence mais a partir do seu envio, alcançando uma amplitude de debates e propondo outros, sempre na perspectiva de sustentar um questionamento e/ou a formulação de novas opiniões críticas. Ao prefaciar a edição das cartas trocadas entre Mário de Andrade e Otávio Dias Leite (IEB/Imprensa Oficial, 2006), Júlio Castañon Guimarães afirma que as cartas

pode haver sempre, por estarem no domínio do privado, a suposição de que guardam informações cuja circulação se dê apenas entre os correspondentes. Quando ocorre de virem a público, seria então como se houvesse uma espécie de revelação. Naturalmente, nem sempre essas informações são tão exclusivas assim, pois podem circular tanto em outras correspondências de cada um dos interlocutores, quanto em outros meios. [...] E aí já se tem pelo menos indício de como o conteúdo de uma correspondência para além de sua dimensão pessoal pode adquirir repercussão mais ampla. Além desses aspectos, as cartas podem ser deflagradoras de massa de informação que não está exatamente presente nelas, que ultrapassa seus limites. (MORAES, 2006, p. 13)
Temos aqui o velho problema entre o privado e o público e a delimitação das fronteiras entre ambos. Mais do que delimitar, percebemos hoje que a publicação destes epistolários produz uma verdadeira práxis de contaminação entre estas mesmas fronteiras, não possibilitando uma separação cartesiana entre ambas, especialmente quando se fala em luta pela justiça, assunto tão caro nesta correspondência entre Frei Betto e Alceu Amoroso Lima.

Ao afirmar que "as cartas podem ser deflagradoras de massa de informação que não está exatamente presente nelas, que ultrapassa seus limites", Júlio Castañon Guimarães toca num aspecto sintomático desta correspondência: o fato de Alceu responder as cartas de Frei Betto com um respectivo artigo na imprensa. Isto é um aspecto digno de se questionar e trazer à lume para discutirmos a linha de alcance da escrita epistolar, pois Alceu realmente aproveitava o que vinha escrito nas cartas de Frei Betto e aproveitava este material para compor as suas crônicas semanais para a imprensa. Vemos claramente uma relação carta-crônica-opinião pública que funcionou muito bem ao longo dos anos que esta correspondência cobriu: 1967-1981.

Desta maneira, confirmamos o que afirmou Geneviève Haroche-Bouzinac (1995), para quem o gênero epistolar se caracteriza por sua natureza profundamente polissêmica e com um "caráter essencialmente híbrido do gênero" (p. 10), possuindo uma forte "instabilidade de suas formas" (Idem), "por isso mesmo sempre em movimento" (Idem), o que necessariamente o leva a ser um "gênero de fronteira". Por todos estes câmbios teóricos e expressivos, a epistolografia possui uma gama de direcionamento analítico, numa constante "corda bamba" que não a relativiza, mas que lhe confere uma múltipla aplicabilidade e uma considerável riqueza de abordagem e performance, considerando o fecundo espaço de debate e discussão gerado por estes textos. 
No caso destas cartas em particular, poderíamos considerar o leitor especializado (o crítico, historiador etc.) como um destinatário em potencial independentemente do destinatário particular? Seria legítimo salvaguardar, sob o peso de processos e testamentos, tais cartas impedindo que pesquisadores e outros leitores tenham acesso ao conteúdo das mesmas? Afinal, quem é (ou pode ser) o destinatário de tais cartas com "função e utilidade" públicas?

São perguntas que não ouso tentar responder em definitivo, apenas especulo aqui eali algumas ideias e até mesmo problemas já ocorridos quando a fronteira do público e do privado sofreu algum tipo de desconstrução.

Aqui falo como pesquisador e organizador de correspondências². E falo a partir de dificuldades reais e materiais perante as quais, nós organizadores de correspondências, somos constantemente obrigados a enfrentar no dia a dia do nosso trabalho, e a maior parte destes problemas decorrem de questões envolvendo o sistema legal brasileiro e a má vontade de certos familiares e algumas instituições que salvaguardam os respectivos acervos, principalmente por conta das dúvidas que decorrem sobre a velha dúvida que motivou este texto - a quem pertence uma carta?

Não raro são as situações que atrapalham a pesquisa epistolográfica, creio que as principais residem nas seguintes questões: a) a nossa Lei de Direitos Autorais, que versa sobre o domínio público intelectual; b) a falta de cooperação de alguns familiares em fornecer autorizações legais para pesquisa, manuseio e publicação de certos acervos e c) a falta de conscientização, por parte de muitos, acerca da importância deste tipo de investigação crítica. Vamos a cada um destes problemas.

\footnotetext{
2 Já organizei três epistolários, a saber: Correspondência Carlos Drummond de Andrade e Alceu Amoroso Lima (UFMG, 2014), Cartas de Ternura em Tempos de Ditadura - Frei Betto e Leonardo Boff Escrevem a Alceu Amoroso Lima (Vozes, 2014) e Correspondência Mário de Andrade e Alceu Amoroso Lima (EDUSP 2015 - em fase de produção com o IEB)
}

A problemática que envolve o domínio público intelectual, no Brasil, gira em torno da Lei 9.610, de 19 de fevereiro de 1998, que legisla sobre os direitos autorais brasileiros. Esta lei é considerada uma das mais avançadas do mundo, entretanto, ela deixa algumas lacunas difíceis de serem resolvidas. A primeira dela é a ausência da noção de autoria em relação aos mais diferentes gêneros da literatura, já que tudo é generalizado na ideia e na expressão "obra literária", inclusive a obra epistolográfica, sequer mencionada. De acordo com o capítulo quinto desta lei, os efeitos da mesma repousam na seguinte perspectiva:

Art. 5o Para os efeitos desta Lei, considera-se:

I - publicação - o oferecimento de obra literária, artística ou científica ao conhecimento do público, com o consentimento do autor, ou de qualquer outro titular de direito de autor, por qualquer forma ou processo. [...]

Já o capítulo sétimo da mesma menciona e legisla sobre o conceito de "obra intelectual":

Art. 7ำ São obras intelectuais protegidas as criações do espírito, expressas por qualquer meio ou fixadas em qualquer suporte, tangível ou intangível, conhecido ou que se invente no futuro, tais como:

I - os textos de obras literárias, artísticas ou científicas;

II - as conferências, alocuções, sermões e outras obras da mesma natureza. [...]

São as únicas referências ao universo de "obra literária" no que concerne às ideias de "efeitos" e "obra intelectual", já que os demais incisos e capítulos versam sobre as demais manifestações artísticas, como o audiovisual, as artes plásticas, a música etc.

Como a pesquisa em torno do Gênero Epistolar é uma atividade relativamente nova no Brasil, para o legislador, o texto da carta não é considerado parte da obra de um artista, mantendo o antigo preconceito de 
que "obra" é especialmente a produção ficcional e publicada de um autor, ou seja, os textos autográficos - cartas, diários, bilhetes, manuscritos em geral - são vistos como a "parte menor" da produção intelectual de uma pessoa; ou como querem alguns teóricos, a sua criação paraliterária, com todas as possibilidades pejorativas deste conceito crítico. Neste embaralhado legislativo, não é raro presenciarmos processos e brigas judiciais quando da publicação de certos textos, como missivas e diários íntimos, embates estes marcados pela tentativa de definição se correspondência é ou não obra literária, bem como a complicada noção de "destinatário múltiplo", especialmente por conta de certos epistolários que possuem informações importantes para se compreender não apenas a história individual do respectivo escritor, mas também a história coletiva e a memória pública de determinados acontecimentos e situações específicas. Neste sentido, a correspondência de historiadores, sociólogos e políticos é particularmente sintomática, pois possuem uma infinidade de informações úteis para se desvendar o próprio processo histórico no qual estão envolvidos e que ajudam a construir.

Quando tais debates se acaloram, é comum recorrermos à noção de domínio público, principalmente no sentido de facilitar o acesso, a pesquisa e a publicação de determinados arquivos pessoais, sem passar pelo périplo burocrático das autorizações de herdeiros e/ou representantes legais do respectivo titular deste acervo. A mesma Lei 9.610 define o nosso conceito legal de domínio público:

Art. 41. Os direitos patrimoniais do autor perduram por setenta anos contados de $1^{\circ}$ de janeiro do ano subsequente ao de seu falecimento, obedecida a ordem sucessória da lei civil.

Art. 43. Será de setenta anos o prazo de proteção aos direitos patrimoniais sobre as obras anônimas ou pseudônimas, contado de $1^{\circ}$ de janeiro do ano imediatamente posterior ao da primeira publicação.
Na tentativa de tornar universais determinados acervos, o estado de domínio público é o sonho de muitos pesquisadores, especialmente por conta de contendas com alguns herdeiros, que nem sempre facilitam a vida do pesquisador, exigindo toda sorte de condições para executar uma autorização legal e, em vários casos, esta permissão nunca é expedida, comprometendo os objetivos de muitas pesquisas e/ou projetos editoriais.

Contudo, esta é uma questão realmente complicada e complexa, que possui inúmeras matizes valorativas e, principalmente, que envolve o fator biografia, algo difícil de obter um consenso. Do ponto de vista ético, creio sinceramente que a abertura irrestrita a determinados acervos pela força de domínio público não seja a solução para todos estes problemas levantados. Penso que o pesquisador deve usar sempre de cautela e bom senso, selecionando e contextualizando as informações obtidas ao longo do seu processo de investigação. Creio que nem "tudo" possa ser publicado, algumas informações - ainda que em prazo legal de domínio público - devem continuar restritas. Quais? Esta resposta dependerá sobre qual objeto se está trabalhando e investigando.

Estou falando de censura? Claro que não, apenas de equilíbrio ético na manipulação dos fatos biográficos de uma pessoa ou de um grupo, de uma história individual ou coletiva.

Estes problemas são comuns e recorrentes quando organizamos uma correspondência: dúvidas, imprevistos, questionamentos pessoais e/ou de terceiros, o drama de selecionar os dados e fatos, a divulgação de certas imagens e textos etc. Sem dúvida, a interrogação sobre a quem pertence uma determinada carta perpassa toda esta problemática, levando-nos a questionar sempre se o destinatário é o único correspondente em si ou qualquer leitor em potencial, independente se este último tinha parte ou não no diálogo epistolar. 
Ao apresentar a correspondência entre Mário de Andrade e Carlos Drummond de Andrade, da qual foi o seu organizador, Silviano Santiago fez algumas sintomáticas considerações que ajudam a problematizar estes assuntos, mas nunca "resolvê-los" por inteiro:

Ao invadir a intimidade da letra epistolar, estamos sendo, antes de tudo, transgressores. Contemplado por convenção jurídica, o limite entre o privado e o público, no tocante à socialidade proporcionada pelo serviço de correios \& telégrafos, é lei clara na cultura do ocidente. A correspondência é inviolável. Às vezes, a linha de demarcação pode ser abolida pelo gesto estabanado de um terceiro. [...] Às vezes, é o correspondente cauto quem reitera o limite entre o público e o privado. Lembro-me de Paul Valéry, precavido diante da língua de trapo de André Gide. Ao final da carta, sente necessidade de aclarar ao correspondente que ela fora escrita 'pour toi', e não 'pour tous'. A publicação póstuma da correspondência de Carlos Drummond de Andrade e Mário de Andrade põe abaixo o 'para ti'. Por várias razões. Nomeemos três. Primeira, em virtude da eminência atingida pela obra dos dois Andrades no campo da estética literária. Segunda, em virtude da importância social e política de Carlos e Mário no seu tempo. Terceira, em virtude da curiosidade intelectual das novas gerações, que saem em busca da verdade nas respectivas obras literárias, mesmo sabendo que, se ela pode se entremostrar na leitura, permanece no entanto escondida e absoluta em cada texto por mais diverso, frio ou incandescente que seja ele. As cartas de escritores também devem ser públicas por um quarto e não tão evidente motivo, já que sua enunciação se passa no campo especializado da teoria literária. Talvez a maior riqueza que se depreende do exame das cartas de escritores advenha do fato de os teóricos da literatura poderem colocar em questão, desconstruir os métodos analíticos e interpretativos que fizeram a glória dos estudos literários no século 20. (SANTIAGO, 2002, p. 9)

Não foi à toa que Silviano nomeou seu ensaio introdutório de "Suas Cartas, Nossas Cartas". Certamente, estes documentos são "nossos" pelos mais diferentes motivos, alguns já antecipados por Silviano, dos quais eu destaco o quarto, isto é, a possibilidade que o estudo de correspondência oferece para uma constante revisão e um repensar a respeito do próprio cânone literário, bem como da historiografia da literatura em si.
Como já evidenciado no início deste texto, estas reflexões não buscam uma solução definitiva para os assuntos levantados, ao contrário, creio que a problematização e o debate dos mesmos sejam mais interessantes, possibilitando novas abordagens e ideias. Certamente, até mesmo pela ainda novidade que a publicação de epistolários provoca, sentimos que aos poucos os estudos epistolográficos vão assumindo o seu lugar e ocupando diferentes espaços nos estudos literários e na cultura como um todo, dialogando com novas estéticas e linguagens, provocando intercâmbios significativos e diálogos bem sintomáticos.

A problemática sobre a quem pertence uma carta é um assunto complexo e que envolve diversos aspectos, especialmente quando se chega à conclusão de que várias cartas possuem uma importância e valor que excedem ao seu próprio destinatário original. São "documentos para amanhã", usando a expressão de Alceu Amoroso Lima, são textos públicos que inicialmente tiveram uma origem individual, direcionada, determinada pela relação remetente-destinatário. Mas essas dimensões muitas vezes se extravasam, adquirem novas categorias e alcançam novos espaços e funções.

Comecei com as especulações presentes no ensaio de Philippe Lejeune 1998) e termino com as minhas próprias interrogações. Pública ou privada, cada vez mais percebemos que a correspondência entre pessoas públicas alcança novos desdobramentos, novos "lugares" nos estudos literários, revitalizando-os cada vez mais.

Como os diários terminam? Como as cartas terminam? A quem pertence uma carta? Perguntas que rondam o imaginário de pesquisadores e organizadores destes textos complexos, híbridos e que possibilitam uma infinidade de abordagens críticas e múltiplas hermenêuticas. No lugar de uma conclusão, uma introdução, uma aposta para se especular o destino da próxima carta que será aberta, lida e interpretada. Afinal, a quem ela pertence? 


\section{Referências}

ANDRADE, Mário de. Cartas a Murilo Miranda. São Paulo: Nova Fronteira, 1981. ANDRADE, Mário de; ALVAREnGA, Oneyda. Cartas. São Paulo: Duas Cidades, 1974.

BAZERMAN, Charles. Letters and the Social Grounding of Differentiated Genres. In: BARTON, D.; HALL, N. (Ed.). Letter Writing as a Social Practice. Amsterdam: John Benjamins Publishing Company, 1999.

BRASIL. Lei 9.610, de 19 de fevereiro de 1998.

CALLIGARIS, Contardo. Verdades de autobiografias e diários íntimos. [texto eletrônico] Disponível em: <www.bibliotecadigital.fgv.br>, 1997.

DIDIER, Béatrice. La correspondance de Flaubert et George Sand. In: Les Amis de George Sand. Paris: Nouvelle Series, 1989.

HAROCHE-BOUZINAC, Geneviève. L'épistolaire. Paris: Hachette, 1995.

KAUFMANN, Vincent. L'équivoque épistolaire. Paris: Éditions de Minuit, 1990.

LEJEUNE, Phippe. How do Diaries End? Disponível em: <http:muse.jhu.edu>.

LEJEUNE, Phippe. Pour l'Autobiographie. Paris: Seuil, 1998.

MORAES, Marcos Antônio de. Cartas, um gênero híbrido e fascinante. In: Jornal da Tarde, São Paulo, 28 nov. 2000. Caderno de Sábado.

MORAES, Marcos Antônio de (Org.). Correspondência Mário de Andrade e Manuel Bandeira. São Paulo: EDUSP, 2001.

MORAES, Marcos Antônio de (Org.). Mário, Otávio - Cartas de Mário de Andrade a Otávio Dias Leite (1936-1944). São Paulo: IEB-USP/Imprensa Oficial/Oficina do Livro Rubens Borba de Moraes, 2006.

MORAES, Marcos Antônio de. Orgulho de Jamais Aconselhar - A Epistolografia de Mário de Andrade. São Paulo: EDUSP/FAPESP, 2007.

RODRIGUES, Leandro Garcia. Alceu Amoroso Lima - Cultura, Religião e Vida Literária. São Paulo: EDUSP, 2012.

RODRIGUES, Leandro Garcia (Org.). Cartas de Esperança em Tempos de Ditadura - Frei Betto e Leonardo Boff Escrevem a Alceu Amoroso Lima. Petrópolis: Vozes, 2015.

RODRIGUES, Leandro Garcia. Uma Leitura do Modernismo - Cartas de Mário de Andrade a Manuel Bandeira. Dissertação (Mestrado) - Pontifícia Universidade Católica do Rio de Janeiro, Rio de Janeiro, 2003.
SANTIAGO, Silviano. "Suas Cartas, Nossas Cartas”. In: ANDRADE, Carlos Drummond de; ANDRADE, Mário de. Correspondência Mário de Andrade e Carlos Drummond de Andrade. Rio de Janeiro: Bem Te Vi, 2002.

SÉRRES, Michel. Écrivains, savants et philosophes font le tour du monde. Paris: Le Pommier 2009.

Recebido em 20 de dezembro de 2014.

Aceito em 12 de março de 2015 . 